This item was submitted to Loughborough's Research Repository by the author.

Items in Figshare are protected by copyright, with all rights reserved, unless otherwise indicated.

\title{
The perceived benefits of community-based group exercise sessions for survivors of stroke
}

PLEASE CITE THE PUBLISHED VERSION

https://doi.org/10.12968/ijtr.2016.0049

PUBLISHER

MA Healthcare Limited

VERSION

AM (Accepted Manuscript)

\section{PUBLISHER STATEMENT}

This document is the Accepted Manuscript version of a Published Work that appeared in final form in International Journal of Therapy and Rehabilitation, copyright @ MA Healthcare, after peer review and technical editing by the publisher. To access the final edited and published work see https://doi.org/10.12968/ijtr.2016.0049.

\section{LICENCE}

CC BY-NC-ND 4.0

\section{REPOSITORY RECORD}

Dam, Seshnee L., and Daniel Rhind. 2020. "The Perceived Benefits of Community-based Group Exercise Sessions for Survivors of Stroke”. Loughborough University. https://hdl.handle.net/2134/12349721.v1. 
The perceived benefits of community-based group-exercise sessions for stroke-survivors

\author{
Seshnee L. Dam ${ }^{1 *}$ and Daniel J.A. Rhind ${ }^{2}$ \\ Brunel University London
}

\begin{abstract}
Author Note
${ }^{1}$ Seshnee L. Dam has acquired an MSc in Sport and Exercise Psychology from Brunel University

London; ${ }^{2}$ Daniel J.A. Rhind is a Reader in Psychology in the School of Sport, Exercise and

Health Sciences, Loughborough University

*Corresponding author. Email: S.L.Dam@2017.ljmu.ac.uk
\end{abstract}

\title{
Acknowledgements
}

The authors are thankful to the stroke-survivors, spousal caregivers, group-exercise coordinators and instructors for their participation in this study. 


\begin{abstract}
Post-stroke physical disability, cognitive impairment and emotional trauma can adversely affect the well-being of survivors. Active participation in group-exercise programmes has been advocated as an intervention to potentially enhance well-being. This study adopted a qualitative approach to explore the experiences of stroke-survivors' participation in ongoing communitybased group-exercise sessions (CBGES) and impact on subjective well-being (SWB). Interviews were conducted with 12 participants from four CBGES. Of these, six were stroke-survivors (4465years) and six other-perspectives comprised caregivers, group-coordinators and/or instructors, closely involved with sessions attended by the stroke-survivors. Thematic analysis revealed that participation in CBGES offered survivors' opportunities for building confidence; enhancing motivation; improving physical ability of affected limbs; enhancing interpersonal relationships; and providing support and knowledge. Participants all agreed that these physical and psychosocial benefits contributed to improving well-being and this supported previous research on the benefits of group work. Paticipants explained how CBGES had facilitated their recovery journey and hence it is recommended that such programmes are made available, accessible and affordable to stroke survivors.

Keywords: stroke-survivors; community-based group-exercise; well-being; confidence; motivation; physical; psychosocial
\end{abstract}




\section{The perceived benefits of community-based group-exercise sessions for stroke-survivors}

Stroke is a leading cause of disability in adults and can result in brain-damage which significantly impacts individuals, families, and society (Simeone et al., 2014; National Stroke Association, 2010). In 2012 Different Strokes, a national charity that supports stroke-survivors, estimated that 157,000 people annually in the UK suffer a stroke or mini-stroke, of which $25 \%$ are under 65years. With this life-changing event survivors can experience complex and longterm physical and psychosocial consequences (Saunders, Greig, \& Mead, 2014). Therefore, a need for improved services and research into interventional techniques exists for the long-term rehabilitation of survivors (Norris, et al., 2013).

A 2013 survey of 2,700 stroke-survivors reported that the emotional effects of stroke were as devastating as the physical effects (Hope, 2013). Only 20\% of stroke patients had received information and practical advice about the resulting emotional impact, whilst $66 \%$ suffered from depression, anxiety, and fear of recurrence. Furthermore, although hospital care was highly rated, $42 \%$ of these survivors felt abandoned and $79 \%$ reported not being advised of the sources of support available for their emotional well-being following discharge, unlike the high support for cancer patients (Hope, 2013). Compared to the general population, strokesurvivors are found to experience a lower sense of well-being and life satisfaction, become isolated and depressed (Ostwald, 2008) and live in fear of a recurrence. Some evidence indicates that multiple and severe health issues that interfere with daily functioning can lower individuals' subjective well-being (SWB). Although lacking clarity, SWB is defined as 'a person's cognitive and affective evaluations of his or her life' (Diener, Lucas, \& Oishi, 2002, p.63; Diener et al., 2003 ) including life satisfaction (Diener, 1984), a broadly-based multifaceted construct (Pavot \& Diener, 2013). Increased satisfaction can include good social support and involvement in valued 
and enjoyed activities (e.g., work, exercise). Intrinsically motivated activities, supported by selfdetermination theory (SDT) contribute to higher SWB for the stimulation and accomplishment they provide (Ryan \& Deci, 2000). While previous research adopted quantitative measures, this study's qualitative approach provided an assessment of situated experiences of SWB, capturing data rich in description via interviews from a broad and comprehensive perspective (Pavot, 2008) that illustrates sensitivity to participants' ongoing-experience and changing circumstances (Pavot \& Diener, 2013). Thus, various interventions to facilitate rehabilitation have been proposed.

Stroke rehabilitation focuses on restoring as much independence as possible by improving physical, mental and emotional functions in a way that preserves the dignity and motivates stroke-survivors to re-learn basic skills such as eating, dressing and walking (NSA, 2010). Comorbidity complexities (e.g., diabetes, cardiovascular, and high blood pressure) could also compound survivors' trauma and drastic changes experienced in their life. One component of rehabilitation is physical activity. Gordon et al. (2004) recommended physical activity and exercise would benefit survivors' both physiologically and psycho-socially. For continuing poststroke recovery, they suggest rehabilitation programmes consider survivors' clinical, emotional and social variations, in their design and implementation. This will ameliorate barriers and other activity-limiting factors (e.g. intrinsic motivation, level of cognitive/physical impairment, etc.) to help survivors reach their optimal state of function and well-being. Argyle (2001) found that exercise which improved short-term mood states and provided better psychological and physical health outcomes, potentially increased long-term SWB. Research involving physical activity (Saunders et al., 2014) and community-based studies (Reed et al., 2012; White et al., 2013; Harrington et al., 2010) show that exercise programmes had positive improvements in physical functions (Cramp et al., 2010; White et al., 2013; Norris et al., 2013) and significantly increased 
participants daily task participation (Patterson et al., 2010). Further research illustrates survivors' motivation, a result of purposeful group-activity, had improved their self-perceived quality of life in terms of confidence, physical ability, psychosocial functioning and a sense of empowerment (Carin-Levy et al., 2009). Lund et al. (2012) reinforce the need for survivors to be proactive in their rehabilitation and recovery, in line with SDT.

Argyle (2001) also found that interventions where interactions with people in group sessions enabled connection further facilitated these benefits, supporting the theory of social activity and participation, a strong life satisfaction predictor, indicating it promotes SWB (Diener \& Seligman, 2002; Fleeson, Malanos, \& Achille, 2002). Even where survivors have achieved significant physical recovery, social isolation can still be evident. Thus, Gordon et al. (2004) recommend survivors seek suitable facilities in the community engaging in group-activity to sustain their long-term interest in exercise and social interaction. Attending group-based sessions involving physical activity may therefore be particularly helpful for stroke-survivors well-being. Community-based group-exercise sessions (CBGES) potentially offer survivors the opportunity to engage in physical activity and receive the social support and understanding of other strokesurvivors.

Cleveland et al.'s (2015) review suggests that physical activity research post-stroke, with less than $10 \%$ of research evaluating or disseminating interventions, is still in the early stages of development. Although many studies have been conducted, evident research from a qualitative perspective with both experiential views, of stroke-survivors as well as their caregivers and/or the group co-coordinators/instructors, is lacking. In exploring participants' experiences of SWB through CBGES-engagement, this study aimed to identify perceived benefits derived from this environment that satisfy survivors' need for autonomy, competence and relatedness underpinned 
by SDT (Ryan \& Deci, 2000). Also, feedback from the other-perspectives can validate survivors' experiences. Following Saunders et al.'s (2014) assertion, the long-term needs of survivors facing life after stroke should be prioritised and addressed by service providers and future research, to effectively provide timely support and tailored-interventions. Post-stroke physical activity is recommended (Billinger et al., 2014) and related programmes should be informed by the experiences of key stakeholders (Mead \& Bernhardt, 2011; Norris et al., 2013) for survivors' adoption, adherence and rehabilitation, crucial to public health service providers and research (Saunders et al., 2014).

\section{Method}

\section{Participants}

A total of 12 participants were interviewed. Of these, a purposive sample of six stroke-survivors were recruited ( 4 females and 2 males) from four CBGES, aged from 44 to 60 -years $(M=51$ years) of Caucasian (3), Black (2) and Asian (1) ethnicities. Stroke-survivors included had experienced their stroke once at least 12-months or longer (with mainly one-sided upper and/or lower limb weakness that affected balance, walking ability, and fatigue, two had experienced severe speech impediments); been discharged from formal rehabilitation services; are attending ongoing-CBGES voluntarily for 6-months minimum; and their ability to engage in low-intensity exercise was sanctioned by their GP. Participants are all ambulatory. A few use walking-aids for support sometimes and a couple use their wheelchair for ease. Participants had all been physically active (i.e. exercise, gym, swimming, running) and in full-time employment prestroke, with one having returned part-time post-stroke.

Table 1 outlines demographics for the other-perspectives participants $(\mathrm{N}=6)$ spousal-caregiver (SPC), group-coordinator (GC), group-instructor (GI) and group-coordinator/instructor (GCI). 


\section{Procedure}

Approval was gained from the University's Ethics Committee prior to data collection. An internet search revealed five UK boroughs providing ongoing CBGES tailored specifically for stroke-survivors. These CBGES offered gentle/low-intensity exercise either Yoga and/or TaiChi/Chi-Kung and/or gym-sessions, which varied amongst boroughs. Four coordinators, of the five contacted, granted permission for the first author to attend an upcoming session to explain the research. Participants attending these CBGES were formally briefed about the study criteria and what participating entailed. Their rights of anonymity, confidentiality, to withdraw from the study and the voluntary nature of the research were clearly explained. Mutually convenient times were arranged with participants meeting the inclusion criteria

Participants were e-mailed the participant information sheet and the consent form prior to the interview. Once the signed consent form had been completed, the interview was conducted. The first author initially began by getting some background information to establish rapport. A semi-structured interview method was employed. An interview guide based on related research (e.g., Carin-Levy et al., 2009; Diener et al., 2003) was developed. The questions were tailored to other-perspectives participants roles (i.e., SPC, GC, GI). The semi-structured nature of the guide provided scope for open-ended answers which enabled in-depth exploration and new information to emerge which ensured the process remained grounded in the reality of the situation. The interviews focused on participants' experiences in relation to key stages of their involvement with the group (e.g., how they found out about it, their feelings prior to attending, their first experiences and their on-going experiences of the sessions). The interviews lasted between 20 to 55-minutes, dependent on participants' willingness to share their experiences and individual response pace. This reflective exploration was audio-recorded, which ensured data was captured 
accurately, and transcribed verbatim. All participants' names and any identifying information has been changed to maintain confidentiality. The interview transcripts were e-mailed to individual participants, to confirm accuracy.

\section{Data Analysis}

The data were transcribed and analyzed according to the guidelines provided by Braun and Clarke (2006). Thematic analysis is a five-stage process through which themes and patterns within qualitative data are identified, analyzed and reported. Firstly, the research team became familiar with the data through reading and re-reading the interviews. Secondly, preliminary codes were then identified through highlighting significant areas of the dataset. Thirdly, the identified codes were then grouped into salient themes. Fourthly, all codes and themes were then reviewed such that their coherence could be assessed. Finally, the emergent themes were defined and given an illustrative label.

A range of strategies were employed to enhance the trustworthiness of this process (Sparkes \& Smith, 2009). Rigour and triangulation of data sources was ensured via feedback obtained from other-perspectives. An independent reviewer and another GCI provided further objective feedback. Participants were given opportunities to comment on the accuracy of the transcription as well as the interpretation of the data with regards to the emergent themes (Holloway and Brown 2012). The research team also held regular meetings to reflect on their expectations and experiences such that any biases could be identified and mitigated against.

\section{Results and Discussion}

The analysis which revealed five higher-order themes: building confidence, enhancing motivation, improving physical ability of affected limbs, enhancing interpersonal relationships, and providing support and knowledge, resonated other group-work findings. Tabular themes 
with sub-themes, presented separately, are supported with survivors' and other-perspectives' quoted responses. The discussion illustrates further relevant participant quoted experiences. An association exists between themes, in shaping participants experiences of CBGES, expressed by Stella, “...the advantages of what I felt made the group good for me...I can't necessarily put my finger on one particular thing, there's lots of things that come together to make it all work."

\section{Building Confidence}

\section{Insert Table 2 here}

Participants unanimously reported that attendance at CBGES had incrementally benefited in building their confidence. Survivors' experienced activity choice and engagement, doing and achieving activities and daily tasks capably, and enjoying social-engagement opportunities. This aligned with autonomy, competence and relatedness, constructs of SDT (Ryan \& Deci, 2000), that suggests survivors' daily needs and life satisfaction were being fulfilled.

This regained confidence may foster feelings of positive self-regard, as Stella reflected, “...(and) with (having) that capability comes confidence, with that confidence comes hope and with that hope comes achievement and all of that...makes you feel better about yourself'. Thus, negative affect reported, e.g., feeling embarrassed, nervous about lost abilities/low confidence, or isolated survivors positively addressed via acceptance of their abilities, exercise-adaptations, and social interactions encouraged by group-participation. Survivors' perceived increased confidence levels experienced, resonated with other-perspectives. CBGES offered survivors opportunities for personal goal-pursuit and achievement, for purposeful activity-engagement and social reengagement that reduced isolation. The positive affect and life satisfaction experienced through survivors' regained confidence levels, are indicators of SWB. These findings support previous research (Carin-Levy et al., 2009; Diener et al., 2002; Diener et al., 2003; Diener, 1984). 


\section{Enhancing Motivation}

\section{Insert Table 3 here}

Survivors concordantly reported that engagement in CBGES resulted in enhancing their motivation. Observing members gainfully doing exercises, setting and achieving specific goals (self-determined and instructor-assessed), and receiving positive encouragement, were factors attributed to their enhanced motivation and improved SWB. Survivors' experiences of enjoying activity-pursuit, achievement, and positive group-members and instructor interactions illustrated autonomy(choice), competence(ability) and relatedness(caring) supporting SDT (Ryan \& Deci, 2000). Survivors acknowledged that witnessing the progressive physical improvement of groupmembers inspired hope and encouragement to commit to their own progress, improvement and recovery, reflected by other-perspectives. As Wendy (GI) attested, "These people are committed to working on their health and well-being and often take other exercises classes as well."

The instructors' practice of regular assessment and review of individual members' goals and progress, in collaborative discussion and agreement of set-goals, demonstrated participants' self-determined recovery choices for regaining independence and sustained activity-engagement. Doris's motivation articulated, “I'm taking responsibility and actions attending (classes) ... I'm taking steps that I can do myself, to assist my rehabilitation, so it's empowering." The reciprocal positive feedback from members and instructors that acknowledged, encouraged and celebrated participants' self-improvements, also enhanced motivation. Participants' positive self-regard from CBGES-participation and feelings of self-worth experienced, derived from helping other survivors, which aided in doing daily life tasks and improving quality of life, also promoted their SWB. These findings concur with extant research (Carin-Levy et al., 2009; Lund et al.,2012; Diener \& Seligman, 2002; Fleeson et al., 2002). 


\section{Improving Physical Ability of Affected Limbs}

Insert Table 4 here

Participants' reported a range of perceived physical benefits such as posture and balance, mobility and flexibility, and muscular strength of their weakened limbs. The sessions facilitated: body awareness and balance, as Ben expressed, “...Chi Kung has helped me to relearn my body positioning I'm more aware of my feet and my legs (and) I'm a lot more balanced than I used to be.”; some functional capabilities being regained in terms of movement and flexibility, claimed by Made, "Doing exercises have helped with some improvements in the mobility of my arm and my leg."; and reacquired muscular strength, illustrated by Doris, "The exercise certainly helps, I can feel (in) my left arm...I'm starting to get some strength back and I'm convinced it's purely down to the exercises that I do. In my shoulder there's now muscle movement, that my husband can feel, whereas before I had absolutely nothing”. Though some participants' physical-activity engagements were restricted by the extent of their disability, those with reported improvements are arguably self-perceived which this study did not specifically measure. The other-perspectives feedback, such as (GC) Andrews', insightfully described systematic progress reviews conducted, "Improvements reviewed at the end of term demonstrates most members are achieving distinct benefits in improved mobility, use of affected limbs, and balance.", validated perceived benefits.

The benefit of increased flexibility from repetition and prolonged activity-engagement had improved participants' functional capacity, increased energy and raised hopes. This aided survivors' independent task performance which positively impacted their daily lives and SWB. These findings support those of previous research (Saunders et al., 2014; Reed et al., 2012; White et al., 2013; Harrington et al., 2010; Cramp et al., 2010; Norris et al., 2013; Patterson et al., 2010; Gordon et al., 2004; Carin-Levy et al., 2009). Participants were not unanimous that 
their physical improvements had resulted solely from CBGES. Survivors' self-determined needs reportedly often warrants complementary activity-pursuits to optimize their recovery.

\section{Enhancing Interpersonal Relationships}

\section{Insert Table 5 here}

Attending CBGES was found to have provided a social benefit to all participants on an individual level, where building friendships led to enhancing their interpersonal relationships, particularly friendships with group-members, groups'-instructor, caregivers and their family. Friendships with group-members, Tina described as, "I feel bonded to them. I feel tight, many (members) of the group phone me.”, Ben claimed, "I've made a number of friends in the group and it's been pretty good to get to know people of different ages and backgrounds.", and Ryan expressed, “(in) the gym class everybody talks, it's good to interact, then I'm not alone, so I've got people here (it) helps (and I'm) not just sitting (alone) at home...I connect (with) people.” The demonstrated closeness, diversity of friendships and connection, participants formed within their group, potentially extends beyond this environment to foster friendships, reduce isolation and enhance survivors' SWB.

Positive relationships were reportedly facilitated by the group-instructor, who listened to, understood the needs, concerns, and limitations voiced by the participants, that Doris illustrated, "The group-instructor assessed me, and we talked about my concerns. I was reassured about my fears she was very clear I could do as much or little as I want. It's a very safe environment.”, this Carla (GI) had resonated, "Upon joining, to set their mind on their recovery we try to understand their social, mental background, past physical and nutritional behaviour." These were addressed to ensure that sessions can be adaptable, non-threatening and more enjoyable. Consequently, this 
increased confidence and self-esteem, encouraged participation and positive interactions with group-members, reflected in other-perspectives responses, suggesting improved survivors' SWB.

The trauma of stroke affects survivors' caregivers and families who often are distressed, beset with worry over the welfare, recovery and well-being of their loved ones, that inadvertently may cause much stress and strain on the quality of relationships. CBGES-involvement reportedly had improved their relationships with their significant others by providing them with knowledge, understanding and reassurance that survivors' engagement in group-activities was enjoyable and aided their recovery. Ben articulated, "My family is now happier for me (knowing) I'm happier and worry less. I've become physically and emotionally better ... group activities help that (it) reassures them... they're supportive of it." Caregivers and families improved relationships, that fostered survivors' SWB, suggests raised awareness and understanding will reciprocally support participants’ CBGES-involvement.

This reported sense of relatedness, supported by SDT (Ryan \& Deci, 2000), may be attributed to increased motivation discussed. These findings concur with research (Gordon et al., 2004) suggesting suitable CBGES provided opportunities for positive social interactions, which enabled member-connection, evidently increased long-term SWB (Argyle, 2001).

\section{Providing Support and Knowledge}

Insert Table 6 here

Participants unanimously claimed their CBGES-involvement provided them with support and knowledge. Their feedback highlighted social support and understanding, group camaraderie and cohesion, and group experiential learning as beneficial.

Having survived a stroke, their similar situations gave them the conviction and trust to openly share information amongst group-members who truly understood. This forum enabled 
shared feelings and concerns with people, not caregivers and medical professionals, expressed by Stella, " being with and talking to people in the group about life experiences, such as depression, anxiety, loneliness, frustration, and anger, with someone other than our carer, and about physical experiences, like lack of movement, getting pins and needles, etc., with someone, who's not a professional, but just someone who's in that same situation as you, is supportive." This insightful peer-support allayed survivors initial fears and addressed their concerns, potentially making them feel better about themselves and recognising their experiences were not unique.

The group-support and peer-understanding, identified by James (SPC), "We have some unique bonds and every member of our group supports each other and understands what's going on through each other's experiences.", was reportedly valued and appreciated more than other sources. It suggests that survivors' need for relatedness, underpinned by SDT, was potentially fulfilled by other survivors. Their trials and tribulations from surviving a similar life-changing event gave them a mutually exclusive understanding that informs their recovery and well-being, further reflected by the other-perspectives.

A sense of caring and being part of a family prevailed. Members attributed this to the group, bonding them by their survival from a traumatic experience and in their common purpose towards gradually overcoming their post-stroke difficulties. Stella explicated this, “...even if my recovery was $100 \%$, I would still keep going because it's the camaraderie and the friendship and this family feeling that it gives me that I just love!’ Some participants considered belonging and 'family feeling' to be as important as the actual exercise classes, as Ben stated, "being part of these groups is more than just physical exercise ... we have an hour of the exercises... then we socialise with refreshments and have days out together". Its' potentially a suggested incentive for continued attendance, since the group-environment also helped reduce feelings of isolation. This 
study found that where some CBGES-design catered for members to get-together following class exercise-sessions, it naturally fostered group-friendships. However, in groups where this was not a feature, members were found to socialise of their own volition as James (SPC) claimed, “...it's just the camaraderie of the group. I'm sure the group feels the same... although ours is purely an exercise group, and a few of us might have a coffee together after, but we do have organised day trips out for the survivors." In both cases the camaraderie, that often extended beyond the groupenvironment, emphasised the value that members attributed to building group-friendships which had promoted their SWB, which was corroborated further by other-perspectives feedback.

Through shared experiences, information and knowledge, our study-participants claimed to have acquired experiential learning from the group-members, within and outside of the groupenvironment, which survivors perceived as beneficial. Survivors deemed this significant since it accorded them practical remedies/ways for doing daily tasks and it served to reduce their undue stress/need to seek medical attention. Ben stated, "If I have questions about medical problems, I'm having post-stroke, instead of going to my doctor, I'm able to ask people at the group who have been through the same experiences and may already have this information.", that Liz (GCI) validated, "The increased social interaction with peers reduces anxiety and stigma associated with having a stroke and disability..., reduced GP visits due to weekly group and tutor contact (is) reducing stress on the NHS." The findings of social support, understanding and friendships derived from CBGES, links relatedness aligned with SDT (Ryan \& Deci, 2000) with survivors' intrinsic motivation to group-activity adherence, supports extant related research (Argyle, 2001; Diener \& Seligman, 2002; Fleeson et al., 2002; Gordon et al., 2004; Carin-Levy et al., 2009). The CBGES group-environment also benefitted survivors' caregivers through support and understanding, group-camaraderie, friendship and experiential learning from their fellow- 
caregivers. James (SPC) expressed, “...group’s been rewarding for us. As a carer I get to talk to the other carers. We off-load on each other like a happy band of brothers, as carers, and we're all friendly, have coffee, do things together. It's very important to me and it pleases my spouse who knows how hard it is for us." The crucial social-support network that sessions provided for them to discuss concerns, successes and their experiential learning, in times of mutual difficulty, had given survivors' peace of mind, potentially benefitting SWB, from knowing their caregivers are also being supported.

\section{General Discussion}

This study explored participants' experiences in CBGES-involvement and aimed to identify the perceived benefits for stroke-survivors. Overall, sessions reportedly enhanced survivors' SWB in five key ways: building confidence; enhancing motivation; improving physical ability of affected limbs; enhancing interpersonal relationships; and providing support and knowledge. The findings suggest participants derived physical and psychosocial benefits from CBGES-engagement which supports previous research (Gordon et al., 2004; Argyle, 2001; Saunders et al., 2014; Cramp et al., 2010; White et al., 2013; Norris et al., 2013; Reed et al., 2012; Harrington et al., 2010; Patterson et al., 2010; Carin-Levy et al., 2009).

In the context of complex post-stroke physical and psychosocial challenges, long-term prospects of recovery and coping with disabilities, this qualitative study provided some insight and raised awareness of participants' lived experiences from ongoing CBGES-involvement and the overall perceived benefits to survivors' SWB. Asserted to include increased life satisfaction (Diener, 1984) from experiencing greater positive affect (Diener, Lucas, \& Oishi, 2002, p. 63;

Diener et al., 2003) enhanced SWB from CBGES-attendance, was supported and illustrated in survivors' comments: Stella, “My 'previous life' was fast-paced, with Yoga exercises being 
holistic, it makes me grateful and thankful for what I have." and Doris, "I get very emotional but actually going to these groups, I have a lot to be thankful for and meeting other stroke-survivors is positive, you realise how lucky you are." The other-perspectives further validated participants' experiences and provided a holistic perspective.

This study contributes to strengthening the theoretical support for such programmes for stroke-survivors. The implications for practice suggest in designing suitable programmes which encourage autonomy, competence and relatedness underpinned by SDT (Ryan \& Deci, 2000), to foster intrinsic motivation and goal-fulfillment, could promote activity-adherence and increased SWB. The programme-design was found to be a crucial influencing factor that contributed to the perceived benefits participants derived across all identified key study-themes. The programmes voluntary nature related to survivors' attendance, participation, choice of offered-activities, and self-determined need to regulate their effort, pace or intensity, and rest if fatigued, had fostered autonomy (i.e., freedom of choice in participation). The programme exercises (low-intensity and/or gym-based) was generally adapted/individualized, cognizant of participants' physical impairments. With their competence needs met, by improving physical ability and daily task performance, this enhanced their SWB. The instructor's role was influential in collaboratively guiding participants to set achievable goals, in this process. Participants' CBGES-involvement proactively recognized in adopting a positive outlook, that they are treated as 'survivors' - not victims - promoting hope during a dynamic journey. Social-interaction opportunities within the programmes aided in building interpersonal relationships and group-camaraderie which fostered relatedness. Though physical exercise was reportedly beneficial to survivors, findings suggest the group-forum itself was considered invaluable for social support, camaraderie and friendship it provided study-participants, that enhanced survivors' SWB. 
Recommendations for the designers of community-based programmes should consider allowing stroke-survivors enough flexibility and choice to promote autonomous participation. Programmes ideally, should provide a variety of stroke-specific general exercises for all groupmembers and tailored-exercises to meet individual goals and diverse needs. Designers should be cognisant of the psychosocial benefits that participants can achieve and ensure their programmes include enough opportunities, to enable social-networking and social-engagement which study participants explicitly valued. Instructors should work collaboratively with participants to guide discussions and set achievable goals. Consideration of these suggestions may optimize survivors' functional abilities and provide psychosocial support opportunities for improving their SWB.

The potential beneficiaries from the outcome of this research include healthcare providers and professionals', organizations that design and promote community-based programmes, and stroke-survivors and caregivers. Raised awareness and perceived value of ongoing CBGES may encourage healthcare professionals and providers that such group-exercise interventions warrant clear signposting and should be made accessible to all stroke-survivors, to maintain their longterm rehabilitation.

An acknowledged limitation of this study is that the participants' reported benefits are self-perceived and were not objectively measured. However, it can be viewed a strength of this qualitative approach, portraying in-depth stroke-survivors' shared-experiences and evaluating programmes from survivors' and other-perspectives' validation. Future research could conduct longitudinal data collection that tracks survivors' experiences, over an extended term, to obtain sustained impact of CBGES on their SWB. The provision in programme-design for caregivers' support-network, which occurs indirectly and informally, can be a future research consideration. The present study was also primarily focused on the perceived benefits of participation. A more 
critical approach could be adopted in future research to explore the challenges of such programmes and the potential for negative experiences associated with participation.

A stroke can have severe physiological, psychological and social consequences for survivors. This study demonstrates that CBGES-programmes can have significant benefits for survivors and help to address some of their challenges. The insights gleaned, will hopefully benefit other stroke-survivors to approach challenges faced, by relating to and being inspired by the study participants' experiences. This could encourage their adoption of group-exercise as a positive path of growth in their rehabilitation, to rekindle their social engagement and interaction to reduce isolation. The shared outcomes of group-exercise experiences that enhanced the SWB of the study's participants could contribute to other survivors' self-awareness, acceptance and acknowledgement of their accomplishments. This could motivate and empower them to continue rebuilding, following a new path in embracing life after stroke. The identified perceived benefits derived from CBGES are not solely physical or psychosocial gains from doing the exerciseprogramme, but collectively provide a holistic experience for stroke-survivors (the whole being greater than the sum of its parts), as sources of support for their physical, mental and emotional well-being through their recovery journey. With increasingly strained health services and an ageing population where stroke in younger people is increasingly prevalent, suitably designed CBGES-programmes encouraging activity-adherence for rehabilitation and support strategies for survivors' SWB is crucial. 
[First Authors Last Name] Page 21

\section{References}

2 Argyle, M. (2001). The psychology of happiness. New York, NY: Taylor \& Francis.

3 Billinger, S. A., Arena, R., Bernhardt, J., Eng, J. J., Franklin, B. A., Johnson, C. M., et al. (2014).

4 Physical activity and exercise recommendations for stroke survivors: a statement for

5 healthcare professionals. Stroke, 45, 2532-2553. doi: 10.1161/STR.0000000000000022

6 Braun, V. \& Clarke, V. (2006). Using thematic analysis in psychology. Qualitative Research in $7 \quad$ Psychology, 3, 77-101.

8 Carin-Levy, G., Kendall, M., Young, A., \& Mead, G. (2009). The psychosocial effects of exercise and relaxation classes for persons surviving a stroke. Canadian Journal of

11 Cleveland, S., Driver, S., Swank, C., \& Macklin, S. (2015). Classifying physical activity research following stroke using the behavioural epidemiologic framework. ManeyOnline, Maneyonline.com doi:http://dx.doi.org/10.1179/10749357142.0000000043

Cramp, M. C., Greenwood, R. J., Gill, M., Lehmann, A., Rothwell, J. C., \& Scott, O. M. (2010). Effectiveness of a community-based low intensity exercise programme for ambulatory stroke survivors. Disability and Rehabilitation, 32, 239-247.

Diener, E. (1984). Subjective well-being. Psychological Bulletin, 95, 542-575. doi:10.3109/09638280903095916

Diener, E., Lucas, R. E., \& Oishi, S. (2002). Subjective well-being: the science of happiness and life satisfaction. In C. R. Snyder \& S. J. Lopez (Ed.), Handbook of positive psychology. Oxford and New York, NY: Oxford University Press. 
1 Diener, E., Oishi, S., \& Lucas, R. E. (2003). Personality, culture, and subjective well-being: emotional and cognitive evaluations of life. Annual Review of Psychology, 54, 403-425. doi:10.1146/annurev.psych.54.101601.145056

4 Diener, E., \& Seligman, M. E. P. (2002). Very happy people. Psychological Science, 13, 81-84.

5 Different Strokes National Charity (2012). Information and support for younger stroke survivors $6 \quad$ from birth to 65. Version 6, July 2012.

7 Fleeson, W., Malanos, A., \& Achille, N. (2002). An intra-individual process approach to the 8 relationship between extraversion and positive affect: is acting extraverted as 'good' as being extraverted? Journal of Personality and Social Psychology, 83, 1409-1422.

10 Gordon, N. F., Gulanick, M., Costa, F., Fletcher, G., Franklin, B. A., Roth, E. J., \& Shephard, T. 11 (2004). Physical activity and exercise recommendations for stroke survivors. Stroke, 35, 1230-1240. doi:10.1161/01.STR.0000127303.19261.19.

13 Harrington, R., Taylor, G., Hollinghurst, S., Reed, M., Kay, H., \& Wood, V. (2010). A community-based exercise and education scheme for stroke survivors: a randomized controlled trial and economic evaluation. Clinical Rehabilitation, 24, 3-15. doi:10.1177/0269215509347437

17 Holloway, I. and Brown, L. (2012). Essentials of a qualitative doctorate. Walnut Creek, CA: 18 Left Coast Press.

19 Hope, J. (2013). 'Half of stroke survivors feel 'abandoned' on leaving hospital' warns leading charity. Medical Correspondent. Mail Online Health. 
1 Lund, A., Michelet, M., Sandvik, L., Wyller, T. B., \& Sveen, U. (2012). A lifestyle intervention as supplement to a physical activity program in rehabilitation after stroke: a randomized controlled trial. Clinical Rehabilitation, 26, 502-512. doi:10.1177/0269215511429473

4 Mead, G., \& Bernhardt, J. (2011). Physical fitness training after stroke, time to implement what we know: more research is needed. International Journal of Stroke, 6, 506-508.

6 National Stroke Association (2010). Hope: the stroke recovery guide. www.stroke.org

7 Norris, M., Kilbride, C., Mohagheghi, A., Victor, C., Jones, T. M., \& Dean, C. M. (2013).

8 Exercise instructor-led functional training programme for community dwelling stroke survivors: a qualitative study. International Journal of Therapy and Rehabilitation, 20,

11 Ostwald, S. K. (2008). Predictors of life satisfaction among stroke survivors and spousal caregivers: a narrative review. Ageing Health, 4, 241-252. doi:10.2217/1745509X.4.3.241

14 Patterson, S. A., Ross-Edwards, B. M., \& Gill, H. L. (2010). Stroke maintenance exercise group: pilot study on daily functioning in long-term stroke survivors. Australian Journal of Primary Health, 16, 93-97.

17 Pavot, W., \& Diener, E. (2013). Happiness experienced: The science of subjective well-being. The Oxford handbook of happiness. Chapter 10, pp134-151.

19 Pavot, W. (2008). The assessment of subjective well-being. In M. Eid and R. Larsen (Eds.), The science of subjective well-being: (pp. 124-140). New York, NY: Guilford Press. 
1 Reed, M. C, Wood, V., Harrington, R., \& Paterson, J. (2012). Developing stroke rehabilitation and community services: a meta-synthesis of qualitative literature. Disability and Rehabilitation, 34, 553-563. doi:10.3109/09638288.2011.613511

Ryan, R. M., \& Deci, E. L. (2000). Self-determination theory and the facilitation of intrinsic motivation, social development, and well-being. American Psychologist, 55, 68-78.

Saunders, D. H., Greig, C. A., \& Mead, G. E. (2014). Physical activity and exercise after stroke: review of meaningful benefits. Stroke, 45, 3742-3747. doi:10.116/STROKEAHA.114.004311

Simeone, S., Savini, S., Cohen, M. Z., Alvaro, R., \& Vellone, E. (2014). The experience of stroke survivors three months after being discharged home: a phenomenological investigation. European Journal of Cardiovascular Nursing. doi: $10.1177 / 1474515114522886$

Sparkes, A. C., \& Smith, B. (2009). Judging the quality of qualitative inquiry: criteriology and relativism in action. Journal of Sport and Exercise, 10, 491-497.

White, J. H., Bynon, B. L., Marquez, J., Sweetapple, A., \& Pollack, M. (2013). Pilot study: 'masterstroke: a pilot group stroke prevention program for community dwelling stroke survivors'. Disability and Rehabilitation, 35, 931-38.doi:10.3109/09638288.2012.717578 
Table 1

Other-perspectives participant (spousal-caregiver (SPC)/group-coordinator (GC)/groupinstructor (GI) or group-coordinator/instructor (GCI)) demographics

\begin{tabular}{|c|c|c|c|c|}
\hline Participant & Gender & Age & Other-perspectives & $\begin{array}{l}\text { Stroke-specific experience } \\
\text { and/or qualification }\end{array}$ \\
\hline James & Male & 66 & Spousal-caregiver (SPC) & 2years 5months \\
\hline Ola & Male & 54 & Spousal-caregiver (SPC) & 1year 4months \\
\hline Andrew & Male & 74 & Group-coordinator (GC) & 5 years \\
\hline $\mathrm{Liz}$ & Female & 41 & $\begin{array}{l}\text { Group-coordinator and } \\
\text { instructor (GCI) }\end{array}$ & $\begin{array}{l}3 \text { years MSc Cardiovascular } \\
\text { Rehab \& L4 Fitness \& Exercise } \\
\text { post Stroke \& Cardiac Rehab }\end{array}$ \\
\hline Wendy & Female & 65 & Group-instructor (GI) & 7 years Tai Chi teacher \\
\hline Carla & Female & 39 & Group-instructor (GI) & $\begin{array}{l}6 \text { years EMT exercise, yoga, } \\
\text { gym and holistic coach }\end{array}$ \\
\hline
\end{tabular}


Table 2

Theme: Building Confidence

\begin{tabular}{|c|c|c|}
\hline $\begin{array}{l}\text { Sub- } \\
\text { themes }\end{array}$ & Participant responses & Other-perspectives responses \\
\hline $\begin{array}{l}\text { To do } \\
\text { things }\end{array}$ & $\begin{array}{l}\text { Made "It's (classes) helped me to be } \\
\text { more independent...and also more } \\
\text { confident to do things (by myself) like } \\
\text { going to Chi Kung class, I walk there } \\
\text { sometimes with my stick." } \\
\text { Tina "...group-environment gives me } \\
\text { the benefit to do what I couldn't do } \\
\text { before." } \\
\text { Stella "...(having) confidence to do and } \\
\text { (being in) the group means that when } \\
\text { you feel disheartened, you know that } \\
\text { there's hope ...that you can do those } \\
\text { things that you need to do, that you } \\
\text { can carry on everyday life." }\end{array}$ & $\begin{array}{l}\text { Ola (SPC) "It (classes) has boosted her } \\
\text { confidence and makes her believe } \\
\text { that, 'you know what, it's one day at a } \\
\text { time but I'm getting better', and now } \\
\text { she's confident, she gets out there." } \\
\text { James (SPC) “I think what the group } \\
\text { has given her (is) confidence to do...to } \\
\text { achieve what she's achieved...(to also) } \\
\text { become involved in another group, } \\
\text { set-up for survivors, ...it gives (her) } \\
\text { that purpose... more confidence to go } \\
\text { there...you know out into the wider } \\
\text { world, being involved with other } \\
\text { people." }\end{array}$ \\
\hline To achieve & $\begin{array}{l}\text { Tina "I (was) doing things slowly, ...I } \\
\text { (can) walk fast now, I (can) do things I } \\
\text { didn't know how to do (post-stroke) } \\
\text {...and it's good for (my) well-being." }\end{array}$ & $\begin{array}{l}\text { Liz (GCI) "Participants are very often } \\
\text { low in confidence (initially) but once } \\
\text { they realise that all exercise can be } \\
\text { adapted for them their confidence } \\
\text { levels increase significantly." }\end{array}$ \\
\hline To socialise & $\begin{array}{l}\text { Doris "I was initially nervous as my } \\
\text { (lack of) balance made me unsure if I } \\
\text { could partake ... most useful for me } \\
\text { going to these group-based exercises } \\
\text { is getting to meet (and) talk to other } \\
\text { stroke-survivors (has) given me hope } \\
\text { of also improving." } \\
\text { Stella "I was embarrassed (at) first, } \\
\text { but (I) soon realised that everyone has } \\
\text { weaknesses and strengths ...and it } \\
\text { gave me a lot of positivity being with } \\
\text { the group." }\end{array}$ & $\begin{array}{l}\text { Ola (SPC) "With all these (classes) I } \\
\text { think it's boosted her confidence, } \\
\text { lifted her spirit ...also improved her } \\
\text { social life." } \\
\text { Andrew (GC) "Our group provides } \\
\text { services, on a self-organised, } \\
\text { voluntary basis, which help enhance } \\
\text { mobility, boost confidence and reduce } \\
\text { the sense of isolation experienced by } \\
\text { stroke-survivors." } \\
\text { Liz (GCI) "Embarrassment is often an } \\
\text { issue but once they come to the } \\
\text { group and see the other participants } \\
\text { this is no longer an issue." }\end{array}$ \\
\hline
\end{tabular}


Table 3

Theme: Enhancing Motivation

\begin{tabular}{|c|c|c|}
\hline $\begin{array}{l}\text { Sub- } \\
\text { themes }\end{array}$ & Participant responses & Other-perspectives responses \\
\hline $\begin{array}{l}\text { Witnessing } \\
\text { progress }\end{array}$ & $\begin{array}{l}\text { Doris "Seeing the improvement (in } \\
\text { stroke-survivors) over the weeks and in } \\
\text { new members too, gives me hope and } \\
\text { encouragement that I am going to } \\
\text { improve as well." } \\
\text { Stella "Seeing how other people } \\
\text { progress through exercise and how I } \\
\text { might progress is very rewarding." }\end{array}$ & $\begin{array}{l}\text { Carla (GI) "Being around people who have } \\
\text { progressed and maintained a better health } \\
\text { also inspires progress in (members) } \\
\text { recovery." } \\
\text { Wendy (GI) "When members come weekly } \\
\text { for several months or longer, it is clear to } \\
\text { see the progress individuals make." }\end{array}$ \\
\hline $\begin{array}{l}\text { Setting } \\
\text { and } \\
\text { achieving } \\
\text { goals }\end{array}$ & $\begin{array}{l}\text { Tina “...they've (goals) helped me ... } \\
\text { before I couldn't walk, now I'm walking } \\
\text { more ... next year I'm going to walk } \\
\text { better." } \\
\text { Ben “...the teacher and I discussed my } \\
\text { aims, I wanted to improve my balance } \\
\text {...the exercises helped me achieve that } \\
\text {....and my progress is assessed... for } \\
\text { areas (I want) to improve further." } \\
\text { Made "To get better and improve and } \\
\text { be as independent as I can be... moving } \\
\text { towards the goal as I say 'a work in } \\
\text { progress' ...positive yes, in terms of as I } \\
\text { said, more mobility" }\end{array}$ & $\begin{array}{l}\text { Carla (GI) "flexible-time frame makes our } \\
\text { long-term outcomes highly possible, (it's) } \\
\text { systematically reviewed, (which) helps us } \\
\text { set medium and short-term outcomes." } \\
\text { Andrew (GC) "Our tutors agree specific } \\
\text { objectives for improvement with all } \\
\text { members (and) reviewed termly, (it) } \\
\text { demonstrates achievements they made." } \\
\text { Ola (SPC) "She aims for whatever she wants } \\
\text { to do and her focus on achieving her goals } \\
\text { is praised by her gym instructor...and going } \\
\text { by herself to the gym...was uplifting for me } \\
\text { (knowing) whilst l'm away she's happy to } \\
\text { do what she needs to, to be independent" }\end{array}$ \\
\hline $\begin{array}{l}\text { Giving and } \\
\text { receiving } \\
\text { feedback }\end{array}$ & $\begin{array}{l}\text { Ben "Being in a group (where) people } \\
\text { make observations about my progress } \\
\text { makes me feel very good... positive and } \\
\text { it's nice to have that feedback and } \\
\text { social feeling ... I needed to go back to } \\
\text { work, that has helped me enormously." } \\
\text { Stella "When we see someone improve } \\
\text { in their walking, their talking, or their } \\
\text { upper limb movement, we all celebrate } \\
\text { that, cheer and encourage them." }\end{array}$ & $\begin{array}{l}\text { Carla (GI) "Stroke-survivors often develop } \\
\text { an idea of what they should work on the } \\
\text { most, to achieve independence but it's } \\
\text { sometimes only because of our influence } \\
\text { and advice - using SMART principle allows } \\
\text { us to forecast and encourage care for the } \\
\text { long term." }\end{array}$ \\
\hline
\end{tabular}


Table 4

Theme: Improving Physical Ability of Affected Limbs

\begin{tabular}{|c|c|c|}
\hline Sub-themes & Participant responses & Other-perspectives responses \\
\hline $\begin{array}{l}\text { Posture and } \\
\text { balance }\end{array}$ & $\begin{array}{l}\text { Tina "Tai Chi...helped me...with my } \\
\text { physical posture..." } \\
\text { Made "(Chi Kung) helps (my) body } \\
\text { in standing and ... with my } \\
\text { balancing." }\end{array}$ & $\begin{array}{l}\text { Andrew (GC) "...(the) improvements... } \\
\text { reviewed at end of term demonstrates } \\
\text { (most) members are achieving distinct } \\
\text { benefits in improved mobility, use of } \\
\text { affected limbs and balance." } \\
\text { Carla (GI) "Ryan has regained (his) } \\
\text { balance, focus, feels the energy to do } \\
\text { extra (weekly) work-outs... (he) gave up } \\
\text { (his) wheelchair and practices walking } \\
\text { with and without a stick for support." }\end{array}$ \\
\hline $\begin{array}{l}\text { Mobility and } \\
\text { flexibility }\end{array}$ & $\begin{array}{l}\text { Ryan "physically...it's been slow... } \\
\text { and really (with) these (exercise) } \\
\text { classes ...my arm was here and... } \\
\text { (he demonstrates from against } \\
\text { upper chest towards hip) can } \\
\text { come right down here...it is now } \\
\text { moving ... it's also good ... for (my) } \\
\text { leg ... I'm happy with that." } \\
\text { Tina "I (was) doing things slowly } \\
\text {...with the exercises I (can) walk } \\
\text { fast now...I am able to lift my } \\
\text { hand...I (can) do things and it's } \\
\text { good for (my) well-being." }\end{array}$ & $\begin{array}{l}\text { Wendy (GI) "Flexibility improves with } \\
\text { repetition and regular participation." } \\
\text { Carla (GI) "Joining the group often } \\
\text { results in rise in hope and therefore } \\
\text { some functional progress e.g., walking } \\
\text { away from the wheelchair, triggering a } \\
\text { limb, moving a bit more, starting to } \\
\text { feel sensation, getting looser, etc." } \\
\text { Liz (GC/I) "We see significant } \\
\text { improvement in functional capacity, } \\
\text { walking ability....and this in turn } \\
\text { positively affects ability to perform } \\
\text { activities of daily living..." }\end{array}$ \\
\hline $\begin{array}{l}\text { Muscle } \\
\text { strength }\end{array}$ & $\begin{array}{l}\text { Made "...massage (in the) gym } \\
\text { classes is very good for my } \\
\text { muscles and gym classes have also } \\
\text { been good for my mobility, } \\
\text { strength in the weak side...(I'm) } \\
\text { able to move more freely... with } \\
\text { the increase of these exercises it's } \\
\text { strengthened my legs (when) } \\
\text { going upstairs, I'm less shaky." }\end{array}$ & $\begin{array}{l}\text { Ola (SPC) "gym exercises have helped } \\
\text { her physically in improving her daily } \\
\text { life. She has more energy...she (now) } \\
\text { comes down and goes (upstairs) } \\
\text { unsupervised." }\end{array}$ \\
\hline
\end{tabular}




\section{$1 \quad$ Table 5}

Theme: Enhancing Interpersonal Relationships

\begin{tabular}{|c|c|c|}
\hline Sub-themes & Participant responses & Other-perspectives responses \\
\hline $\begin{array}{l}\text { Group } \\
\text { members }\end{array}$ & $\begin{array}{l}\text { Made "We have a friendly relationship } \\
\text { we call each other, if somebody wasn't } \\
\text { there, and say I hope you're okay" } \\
\text { Stella "Members within the group are } \\
\text { friendly with each other ... for social } \\
\text { reasons or hobbies, ...look out for each } \\
\text { other... we phone (to) find out how } \\
\text { they're doing...that experience is good." }\end{array}$ & $\begin{array}{l}\text { Ola (SPC) "These classes have lifted her } \\
\text { spirit ... friendships (and) engagement } \\
\text { with people (there) has also improved } \\
\text { her social life" } \\
\text { James (SPC) "I think like all groups some } \\
\text { (members) are very happy to be friendly } \\
\text { and so she has become friendly." }\end{array}$ \\
\hline $\begin{array}{l}\text { Group } \\
\text { instructor }\end{array}$ & $\begin{array}{l}\text { Ben "She listens to individual needs ... } \\
\text { tailors her classes to help the needs of } \\
\text { the group ... we have a very good } \\
\text { relationship." } \\
\text { Stella "The instructor and I have got on } \\
\text { so well (that) I attend her mainstream } \\
\text { yoga class and she knows about each } \\
\text { person's stroke; how it has affected } \\
\text { them, what their limitations and goals } \\
\text { and achievements are... and that's my } \\
\text { relationship with her." }\end{array}$ & $\begin{array}{l}\text { James (SPC) "I think what the group has } \\
\text { introduced her to is the inspirational } \\
\text { yoga instructor ... (and this) has given } \\
\text { her more confidence to go there, out } \\
\text { into the wider world, being involved } \\
\text { with other people." } \\
\text { Ola (SPC) "She finds her instructors' } \\
\text { support really uplifting (and) physically } \\
\text { when she's doing something... her } \\
\text { (instructors') input has been great!" }\end{array}$ \\
\hline $\begin{array}{l}\text { Caregivers } \\
\text { and family }\end{array}$ & $\begin{array}{l}\text { Doris "My children were distressed about } \\
\text { long-term effects. I tried to explain to } \\
\text { them some (members) are a lot older } \\
\text { than I...and why their recovery has been } \\
\text { longer so, they stopped worrying and are } \\
\text { trying to understand." }\end{array}$ & $\begin{array}{l}\text { Liz (GCI) "We have anecdotal evidence } \\
\text { of improved mood which has positively } \\
\text { impacted a marriage" }\end{array}$ \\
\hline
\end{tabular}


1 Table 6

Theme: Providing Support and Knowledge

\begin{tabular}{|c|c|c|}
\hline Sub-themes & Participant responses & Other-perspectives responses \\
\hline $\begin{array}{l}\text { Social support } \\
\text { and } \\
\text { understanding }\end{array}$ & $\begin{array}{l}\text { Made “From my own experience, } \\
\text { going to these (CBGES), I don't feel I'm } \\
\text { just on (my) own without support. I } \\
\text { have this, at home, but in terms of } \\
\text { meeting with people who have a } \\
\text { similar experience as me it's helpful, } \\
\text { we can understand each other and } \\
\text { support each other." }\end{array}$ & $\begin{array}{l}\text { Ola (SPC) "She's in a place where people who } \\
\text { can identify with what she's going through } \\
\text { helps (and) from this interaction information } \\
\text { that's been exchanged has really helped her } \\
\text { (and by) talking to and informing others she's } \\
\text { become more helpful." }\end{array}$ \\
\hline $\begin{array}{l}\text { Group } \\
\text { camaraderie } \\
\text { and cohesion }\end{array}$ & $\begin{array}{l}\text { Stella "The social aspect of sitting and } \\
\text { having tea, going for lunch afterwards } \\
\text { and sometimes (the group) go out for } \\
\text { the day, is good." } \\
\text { Tina "I couldn't do without attending } \\
\text { these sessions for } 1 \text { week (because) ...I } \\
\text { see everybody... I speak to people...we } \\
\text { eat, we drink tea, we talk, and I laugh a } \\
\text { lot...it's good for me... and (the) group } \\
\text { outings." }\end{array}$ & $\begin{array}{l}\text { James (SPC) "For me it's the camaraderie } \\
\text { that's there, it's knowing you're not isolated } \\
\text {...there are people out there you can share } \\
\text { with." } \\
\text { Wendy (GI) "The class is designed to allow } \\
\text { for tea and coffee after class where members } \\
\text { can meet informally, share information and } \\
\text { build friendships." }\end{array}$ \\
\hline $\begin{array}{l}\text { Group } \\
\text { experiential } \\
\text { Learning }\end{array}$ & $\begin{array}{l}\text { Stella "helps with everyday challenges } \\
\text {...you can now do... finding a technique } \\
\text { from the group or practising doing it... } \\
\text { makes that so great." }\end{array}$ & $\begin{array}{l}\text { Andrew }(\mathrm{GC}) \text { "By sharing our experience of } \\
\text { stroke, we learn from each other, exchange } \\
\text { coping strategies and discover new skills and } \\
\text { values that equip us to move back into the } \\
\text { world." }\end{array}$ \\
\hline
\end{tabular}

